\title{
Beta-Adrenergic Agonists Increase Lung Liquid Clearance in Anesthetized Sheep
}

Yves Berthiaume, Norman C. Staub, and Michael A. Matthay

Cardiovascular Research Institute and Departments of Medicine and Physiology,

University of California at San Francisco, San Francisco, California 94143

\begin{abstract}
We did experiments to determine whether beta-adrenergic agonists increase lung liquid clearance in anesthetized ventilated adult sheep and, if so, whether the increase is mediated by beta receptors and what mechanism is involved. We instilled $100 \mathrm{ml}$ of autologous serum either alone or with a beta-adrenergic agonist (terbutaline, $10^{-5} \mathrm{M}$, or epinephrine, $5.5 \times 10^{-6} \mathrm{M}$ ) into one lower lobe. After $4 \mathrm{~h}$ both terbutaline and epinephrine increased lung liquid clearance. The increase in lung liquid clearance was inhibited when propranolol (a beta blocker) or amiloride (a sodium channel blocker) was added to the terbutaline. Increased clearance was not explained by changes in pulmonary hemodynamics, pulmonary blood flow, or lung lymph flow. We conclude that beta-adrenergic agonists increase lung liquid clearance in anesthetized intact adult sheep. This increase is mediated through beta receptors and probably depends on increased active transport of sodium across the alveolar barrier.
\end{abstract}

\section{Introduction}

Clearance of liquid across the alveolar barrier of the lungs depends in part on hydrostatic and osmotic pressure gradients across the alveolar barrier $(1,2)$. Recently, it has been suggested that alveolar and lung liquid clearance may also depend on active metabolic processes for ion transport (3-5). This hypothesis is supported by work in different experimental models in which the presence of active sodium transport has been identified $(6-10)$.

In some studies, active transport of sodium has been shown to increase when beta-adrenergic agents are present. For example, beta-adrenergic agonists increase sodium transport across the alveolar barrier in fetal lambs (11), isolated rat lungs (12), and cultured alveolar type II cells $(7,13)$. However, whether increased active transport of sodium induced by beta-adrenergic agents increases lung liquid clearance in the intact adult animal has never been studied. Therefore, our first objective in these studies was to determine whether beta agonists increase lung liquid clearance in anesthetized intact adult sheep.

Once it was clear that beta agonists markedly increased lung liquid clearance, we established that this effect is mediated through beta receptors. Then, we studied the mechanism for the

Address reprint requests to Michael A. Matthay, CVRI, M-1327, UCSF, San Francisco, CA 94143-0130. 1986.

Received for publication 12 May 1986 and in revised form 18 August

J. Clin. Invest.

(c) The American Society for Clinical Investigation, Inc.

0021-9738/87/02/0335/09 \$1.00

Volume 79, February 1987, 335-343 increased liquid clearance by measuring pulmonary hemodynamics, pulmonary blood flow, lung lymph flow, and alveolar barrier permeability and surface area. Finally, to evaluate whether the mechanism of the increased lung liquid clearance we observed involves an increase in active sodium transport, we assessed the effect of the sodium channel blocker amiloride on the beta agonist-mediated increase in lung liquid clearance.

\section{Methods}

Surgical preparation. We anesthetized 50 female and wethered yearling sheep $(34.9 \pm 5.6 \mathrm{~kg})$ with intravenous sodium pentothal $(30 \mathrm{mg} / \mathrm{kg})$, made a tracheostomy, and inserted a cuffed tracheostomy tube (Portex, Inc., Wilmington, MA). The lungs were ventilated with a constant-volume pump (Harvard Apparatus Co., Inc., South Natick, MA) at a tidal volume of $400-500 \mathrm{ml} \mathrm{(13-15} \mathrm{ml/kg)} \mathrm{with} \mathrm{a} \mathrm{peak} \mathrm{inspiratory} \mathrm{pressure} \mathrm{of} 15-20$ $\mathrm{cm} \mathrm{H}_{2} \mathrm{O}$ and a positive end-expiratory pressure of $5 \mathrm{~cm} \mathrm{H}_{2} \mathrm{O}$. The respiratory rate was adjusted to achieve a $\mathrm{PaCO}_{2}$ between 30 and $40 \mathrm{mmHg}$. Anesthesia was maintained by $1.0-1.5 \%$ halothane mixed with supplemental oxygen (40-60\%). The sheep were paralyzed with pancuronium bromide (1.0-mg i.v. every $3 \mathrm{~h}$ ).

The preparation of anesthetized sheep designed to collect lung lymph and measure systemic and pulmonary hemodynamics was similar to the one previously published $(3,14,15)$. The preparatory surgery required 1.5-2 $\mathrm{h}$. The sheep were then placed in the prone position, and the head and thorax were tilted up at a $5^{\circ}$ angle to maintain the lower lung lobes in a slightly dependent position. Both sides of the chest were left open.

Preparation and instillation of serum. The procedures for preparation and instillation of the serum solution are essentially the same as we have previously published $(3,5)$. Briefly, on the day before the experiment $250 \mathrm{ml}$ of blood was withdrawn from the sheep with sterile technique. The blood was clotted and centrifuged to obtain $125 \mathrm{ml}$ of serum. The serum was refrigerated overnight. The next morning, we added $30 \mathrm{mg}$ of anhydrous Evans blue to bind to the albumin (16). $20 \mu \mathrm{Ci}$ of ${ }^{125} \mathrm{I}$ labeled human serum albumin (Mallinckrodt, Inc., St. Louis, MO) was added to the serum as a protein tracer. Before we instilled the serum, we took a sample for total protein measurement and wet/dry ratio measurements so that the dry weight could be subtracted from the final lung water calculations. Our aim was to instill $100 \pm 3.0 \mathrm{ml}$ of water (108-112 $\mathrm{ml}$ of serum volume). The serum was instilled by inserting a flexible fiberoptic bronchoscope (Machida America, Inc., Norwood, NJ) through a three-way t-piece adapter via the tracheostomy so that ventilation was not interrupted. Either the left or the right lower lobe was used to instill the serum. The instillation took $\sim 5-10 \mathrm{~min}$.

General protocol. Five series of experiments were done. In the first three series, we evaluated the effects of two beta-adrenergic agonists and a beta-adrenergic antagonist on the clearance of liquid and protein from the lungs. In the last two series, we studied the effects of changes in pulmonary blood flow and the effect of a sodium channel blocker (amiloride) on the beta agonist-mediated increase in lung liquid clearance. In addition, in each of these series we measured pulmonary hemodynamics and lung lymph flow to evaluate their possible role as a mechanism of the increased lung liquid clearance induced by the beta-adrenergic agonist. In each of these series, the permeability of the alveolar barrier was assessed by measuring protein clearance using ${ }^{125} \mathrm{I}$-albumin mixed with the instilled serum. 
For all the experimental series, we used the following general protocol. After surgery there was a baseline period of 1.5-2 $\mathrm{h}$, during which lung lymph flow and vascular pressures were stable. Then the serum solution with or without a beta-adrenergic agonist or antagonist was instilled. During the next $4 \mathrm{~h}$, systemic, pulmonary, and left atrial pressures, cardiac output, and lung lymph flow were measured every $15 \mathrm{~min}$. Blood and lymph samples were taken every $0.5 \mathrm{~h}$ for total protein concentration measurements and ${ }^{125} \mathrm{I}$-albumin counts. After $4 \mathrm{~h}$, the sheep were killed and the lungs were removed for sampling of the airway liquid to obtain the final airway liquid protein concentration, measurements of excess lung water to assess lung liquid clearance, and the residual quantity of ${ }^{125}$ I-albumin left in the lung (see Measurements).

\section{Specific protocols}

Series 1. Instilled beta-adrenergic agonists (18 sheep). To determine the effect of beta-adrenergic agonists on lung liquid and protein clearance from the lungs, we instilled into one lower lobe either serum alone (six sheep), serum mixed with terbutaline $\left(10^{-5} \mathrm{M}\right.$; CIBA-GEIGY, Summit, $\mathrm{NJ})$ (six sheep), or serum mixed with epinephrine $\left(5.5 \times 10^{-6} \mathrm{M}, \mathrm{Am}\right.$ Quinine, Shirley, NY) (six sheep). We then measured the variables described in the general protocol. The doses of terbutaline and epinephrine selected for these studies are similar to the doses used in studies of isolated alveolar type II cells by other investigators $(7,13)$.

Terbutaline and epinephrine were chosen because of their previous use in other models. Terbutaline was used to study the electrical properties (7) and dome formation $(7-10)$ by cultured alveolar type II cells. Terbutaline was also used to study sodium transport in the isolated, perfused rat lung (12). Finally, epinephrine was used to study the reabsorption of fetal lung liquid after birth (11). We also selected epinephrine because it is an endogenous cathecolamine.

Series 2. Intravenous and instilled beta-adrenergic agonists (six sheep). To determine whether we could achieve a greater effect on lung liquid and protein clearance by giving terbutaline both in the instilled serum and intravenously, we did two experiments. First, in preliminary experiments, terbutaline was infused to determine whether an intravenous infusion increases lung liquid clearance. For this first experiment, after the baseline period, an intravenous infusion of terbutaline was begun in three sheep at a dose of $0.6 \mu \mathrm{g} \cdot \mathrm{kg}^{-1} \cdot \mathrm{min}^{-1}, 1 \mathrm{~h}$ before the serum instillation. Then we instilled serum alone into one lower lobe, and continued the intravenous infusion of terbutaline for $4 \mathrm{~h}$ more and measured variables as described in the general protocol. The dose of terbutaline is identical to the dose that was used previously in unanesthetized sheep and did not produce major changes in hemodynamics (17).

Second, since an intravenous infusion of terbutaline increased lung liquid clearance modestly, in three additional sheep we gave terbutaline both intravenously $\left(0.6 \mu \mathrm{g} \cdot \mathrm{kg}^{-1} \cdot \mathrm{min}^{-1}\right)$ and mixed in the serum $\left(10^{-5}\right.$ M) to determine if it would have an additive effect on lung liquid clearance. The protocol was the same as the one just described for intravenous terbutaline except that terbutaline was also added to the instilled serum.

Series 3. Beta-adrenergic antagonist (eight sheep). Two experiments were done in series 3 . First, to determine whether beta-adrenergic blockade alone has an effect on lung liquid clearance, we gave the beta-adrenergic antagonist propranolol intravenously to four sheep and mixed it with the instilled serum to assure maximal beta blockade. For this experiment, intravenous propranolol was begun at a low dose $\left(5 \mu \mathrm{g} \cdot \mathrm{kg}^{-1} \cdot \mathrm{min}^{-1}\right) 1$ $h$ before the serum instillation and was gradually increased to a maximum of $21 \mu \mathrm{g} \cdot \mathrm{kg}^{-1} \cdot \mathrm{min}^{-1}$ in an effort to maintain left atrial pressure at $<10$ $\mathrm{cm}_{2} \mathrm{O}$. Beta blockade was tested with isoproterenol (18). After propranolol had been infused at a stable dose for $1 \mathrm{~h}$, serum mixed with propranolol ( $10^{-5} \mathrm{M}$ in three sheep; $10^{-4} \mathrm{M}$ in one sheep) was instilled into the lung. The infusion of propranolol was continued for $4 \mathrm{~h}$ after serum instillation while the variables described in the general protocol were measured.

Second, to confirm that the effects induced in the experiments of series 1 and 2 were mediated through beta receptors, the beta-adrenergic response was inhibited in four other sheep by giving propranolol and terbutaline together. For this experiment, propranolol was infused intravenously for $1.5 \mathrm{~h}$, then an intravenous infusion of terbutaline (as described for series 2 experiments) was begun. After $1 \mathrm{~h}$ of terbutaline infusion, serum mixed with both terbutaline $\left(10^{-5} \mathrm{M}\right)$ and propranolol $\left(10^{-5} \mathrm{M}\right)$ was instilled into one lung. The intravenous infusions of propranolol and terbutaline were continued throughout the 4-h study period while the variables described in the general protocol were measured. Beta blockade again was confirmed with isoproterenol (18).

Series 4. Pulmonary blood flow (14 sheep). To determine the possible role of pulmonary blood flow in the increased lung liquid clearance observed with beta-adrenergic agonists, we did two experiments. In the first experiment, we studied the distribution of pulmonary blood flow to the serum-instilled lung by injecting radioactive microspheres (see Measurements) into 10 sheep that received either serum alone (two sheep), serum mixed with epinephrine (three sheep), serum mixed with terbutaline and intravenous terbutaline (two sheep), or serum alone and intravenous nitroprusside (three sheep).

Since the vasodilator nitroprusside and beta-adrenergic agonists maintained pulmonary blood flow to the serum-instilled lung, nitroprusside was infused in the second series of experiments (four sheep) to see if preserved pulmonary blood flow by itself would increase lung liquid clearance. First, to find a dose of nitroprusside that would increase blood flow to the serum-instilled lung, a brief period of hypoxia-induced pulmonary hypertension was created and the dose of nitroprusside (Abbott Laboratories, Irving, TX) that would return pulmonary artery pressure to baseline levels was determined. Briefly, after the surgical preparation was complete, the fraction of oxygen was lowered to 0.10 , resulting in a mean arterial oxygen tension of $31.8 \pm 1.7$ (SD) mmHg. Pulmonary artery pressure rose to $31.5 \pm 5.3 \mathrm{~cm} \mathrm{H}_{2} \mathrm{O}(n=4)$, and pulmonary vascular resistance doubled. After $10 \mathrm{~min}$ of alveolar hypoxia, intravenous nitroprusside was begun at a dose of $3 \mu \mathrm{g} \cdot \mathrm{kg}^{-1} \cdot \mathrm{min}^{-1}$ and was increased until pulmonary artery pressure returned to baseline levels. This objective was accomplished in all sheep within $10 \mathrm{~min}$, with an average dose of nitroprusside of $5 \mu \mathrm{g} \cdot \mathrm{kg}^{-1} \cdot \min ^{-1}$ (range, 4-7 $\mu \mathrm{g} \cdot \mathrm{kg}^{-1} \cdot \min ^{-1}$ ).

The effect of infusion of this dose on lung liquid clearance was studied as follows. We stopped the intravenous nitroprusside infusion, after which the oxygen fraction returned to 0.50 . Then the baseline period was started and continued for $2 \mathrm{~h}$. Next, the nitroprusside infusion was begun. After $0.5 \mathrm{~h}$, serum alone was instilled into one lung. The infusion of nitroprusside was continued for $4 \mathrm{~h}$ and the variables described in the general protocol was measured.

Series 5. Sodium channel blocker, amiloride (four sheep). To determine the possible role of active transport of sodium in the increased clearance of liquid observed with terbutaline, we instilled in four sheep serum mixed with terbutaline $\left(10^{-5} \mathrm{M}\right)$ and the sodium channel blocker amiloride (Merck Sharp and Dohme, West Point, PA) $\left(10^{-3} \mathrm{M}\right.$ in two sheep; $10^{-4} \mathrm{M}$ in two sheep) and measured the variables described in the general protocol. The doses of amiloride were similar to those used in isolated type II cell preparations (7) to block the uptake of sodium at the apical side of the cell membrane. These were also the doses of amiloride used in previous studies in anesthetized sheep in our laboratory (2).

\section{Measurements}

Measurements of hemodynamics, lung lymph flow, and protein concentration. We measured left atrial, pulmonary arterial, systemic arterial, airway pressure, cardiac output, and blood gases as previously described (3). At 15-min intervals we measured the volume of lymph, and at 30min intervals we collected the lymph and a blood sample to measure total protein concentration with an automated analyzer (AAII Technicon, Tarrytown, NY).

Excess lung water measurements. After each experiment, we obtained a 40-ml blood sample to measure the hemoglobin concentration and the wet/dry weight ratio of blood for the lung water calculation. Then the sheep was killed by cross-clamping the aorta. The trachea was clamped at an airway pressure of $20 \mathrm{~cm} \mathrm{H}_{2} \mathrm{O}$ and the lungs were removed from the thorax. Airway liquid $(2-5 \mathrm{ml})$ was obtained by passing a 3- $\mathrm{mm}-$ diameter catheter into the distal airways of the serum-instilled lung. The sample was centrifuged and the total protein concentration and radioactivity (counts per milliliter) of the supernatant was measured. Then 
the lungs were frozen in liquid nitrogen. The next day, each lung was examined in a cryostat at $-20^{\circ} \mathrm{C}$ to determine the distribution of the Evans blue-labeled serum and to confirm that none of the fluid had spilled over into the control lung.

We then homogenized each lung separately and determined the extravascular lung water by calculating the wet/dry weight ratio (grams $\mathrm{H}_{2} \mathrm{O} /$ grams dry lung) (19). The excess water in the experimental lung was then calculated with the same equation as described previously (3, 5). To evaluate the accuracy of this method of measuring different quantities of water instilled into the lung, we did five experiments in which different quantities of water $(40-100 \mathrm{ml})$ were instilled into an excised lung. The other lung was used as a control. Then the known instilled water volume was plotted against the measured water volume. A regression line was calculated and the coefficient of variation was computed from the standard error of the estimate of the regression line and the mean values of the residual lung water. The coefficient of variation for this technique was $11.1 \%$.

Distribution of pulmonary blood flow. To quantify the distribution of pulmonary blood flow to the serum-instilled regions of the lungs, we measured the fractional distribution of pulmonary blood flow in 10 sheep (serum alone in two sheep; serum plus epinephrine in three sheep; serum plus intravenous terbutaline mixed with instilled serum in two sheep; serum plus intravenous nitroprusside in three sheep). To measure the fractional distribution of pulmonary blood flow, $15-\mu \mathrm{m}$-diameter radionuclide-labeled microspheres were injected over $0.5 \mathrm{~min}$ into the right atrium as described previously $(3,20)$. Measurements were made twice during the last half hour of the baseline period before serum was instilled. Then measurements were made at $0.5,1,2$, and $4 \mathrm{~h}$ after the serum was instilled. In studies where an intravenous infusion was started before serum was instilled, two measurements were made $10 \mathrm{~min}$ before the serum instillation, and only one baseline measurement (no infusion) was made.

In a cryostat, the serum-instilled lung was cut and the homogeneously blue-stained areas were isolated. This permitted us to identify the maximum change in local blood flow that had occurred, as we have done previously (3). This homogeneously blue-stained area contained $\sim 70 \%$ of the liquid instilled. The other portions of the experimental lung, which contained $30 \%$ of the instilled liquid, and the entire control lung were then isolated. Each portion was homogenized and carbonized. The samples were then processed for radionuclide counting of the isotopes (20). We accounted for $88.3 \pm 9.1 \%$ (SD) of the radioactive isotopes that were injected.

Alveolar permeability and surface area. To assess the permeability of the alveolar barrier, three different methods were used: clearance of protein ( ${ }^{125} \mathrm{I}$-albumin) from the air spaces, accumulation of plasma equivalents in the air spaces, and clearance of a small molecule ( $\left[{ }^{57} \mathrm{Co}\right]$ cyanocobalamine) from the air spaces. For the assessment of protein clearance, $20 \mu \mathrm{Ci}$ of ${ }^{125} \mathrm{I}$-human serum albumin was added to the instilled serum. The method for assessing the total amount of tracer albumin instilled and the residual amount of tracer recovered in homogenized lung, lymph, and plasma is similar to the method previously published $(3,5)$. The sum of the amounts of tracer in the homogenized lung, lymph, and plasma accounted for $95.9 \pm 4.2 \%$ (SD) of the instilled tracer.

The permeability was assessed also by examining the accumulation of plasma equivalents in the air spaces. For this measurement, we assessed the movement of protein from the vascular spaces into the air spaces in selected studies by labeling the plasma with ${ }^{131} \mathrm{I}$-human serum albumin at the beginning of the experiment and then counting the accumulation of ${ }^{131} \mathrm{I}$-albumin in the airway liquid at the end of the experiment. This method has been previously used to estimate clearance of plasma into the air spaces of the lungs $(5,21)$. Briefly, $30 \mu \mathrm{Ci}$ of ${ }^{131} \mathrm{I}$-albumin (E. R. Squibb \& Sons, Inc., New Brunswick, NJ) were injected intravenously $1 \mathrm{~h}$ before instilling serum into 19 sheep (serum alone in three sheep; terbutaline in seven sheep; epinephrine in three sheep; propranolol in two sheep; nitroprusside in two sheep; amiloride plus terbutaline in two sheep). Then the counts of ${ }^{131} \mathrm{I}$-albumin per milliliter in all plasma samples were measured and a mean value for the 4-h experimental period after serum instillation was calculated. Then the counts per milliliter in the airway liquid retrieved at $4 \mathrm{~h}$ were measured. To estimate clearance of plasma into the air spaces, the amount of plasma equivalents in air spaces was calculated with a modified version of the equation we have used before $(5,21)$ : $\mathrm{ml}$ of plasma equivalents in air spaces $=\left({ }^{131} \mathrm{I}\right.$-albumin/ $\mathrm{ml}$ of airway liquid $\times$ excess lung water) $/{ }^{131} \mathrm{I}$-albumin $/ \mathrm{ml}$ of plasma. This equation assumes that all the measured excess lung water is in the air spaces, a reasonable assumption because of the similarity between measured and estimated lung water (see Discussion).

Finally, to evaluate changes in the permeability or the surface area of the alveolar barrier that might not be detected by protein clearance ( ${ }^{125}$ I-albumin), the clearance of a smaller molecular weight tracer, $\left[{ }^{57} \mathrm{Co}\right.$ ]cyanocobalamine $(1,355 \mathrm{~mol} \mathrm{wt})$, was studied in seven sheep from series 1 (serum alone in three sheep; serum mixed with terbutaline in two sheep; serum mixed with epinephrine in two sheep). This tracer has been used by other investigators for the same purpose (22-24). We instilled $3 \mu \mathrm{Ci}$ of $\left[{ }^{57} \mathrm{Co}\right]$ cyanocobalamine (Amersham Corp., Arlington Heights, IL) and measured its clearance from the air spaces parallel to the clearance of ${ }^{125} \mathrm{I}$-albumin. To prevent binding of the radioactive cyanocobalamine molecule to the transcobalamine-binding protein present in the lungs, the sheep were saturated with $1,000 \mu \mathrm{g}$ of cold vitamin $B_{12}$ (Elkins-Shinn, Inc., Cherry Hill, NJ) i.m. $16 \mathrm{~h}$ before the experiment and $1,000 \mu \mathrm{g}$ i.v. $1 \mathrm{~h}$ before serum instillation. The total amount of $\left[{ }^{57} \mathrm{Co}\right]$ cyanocobalamine in the lungs, lymph, urine, and plasma was determined as previously described for ${ }^{125} \mathrm{I}$-albumin tracer $(3,5)$. Using this technique, we accounted for $93.8 \pm 8.1 \%$ of the tracer instilled.

Statistics. The data are summarized as the mean and standard deviation. For series 1 experiments, all the data from the serum alone (six sheep), serum mixed with terbutaline (six sheep), and serum mixed with epinephrine (six sheep) experiments were analyzed with a one-way analysis of variance and the Newman-Keuls multiple range test (25). Oneway analysis of variance and the Newman-Keuls test were also used to compare data from the experiments in series $2,3,4$, and 5 with data from the six-serum-alone experiments from series 1 . The changes in hemodynamics and lymph flow from the baseline to the experimental period within each group were analyzed with Student's paired $t$ test. For the baseline period, we used data from the last hour, but for the experimental period we used all four hours. We regarded as significant those differences with a $P$ value of $<0.05$.

\section{Results}

Instilled beta-adrenergic agonist effects. Beta-adrenergic agonists increased lung liquid clearance. When either terbutaline or epinephrine was instilled along with serum into the air spaces, the excess lung water was significantly less than when serum alone was instilled (Fig. $1 A$ ). Although the mean excess lung water for the terbutaline experiments was $12 \mathrm{ml}$ less than that for the epinephrine experiments, the difference did not reach statistical
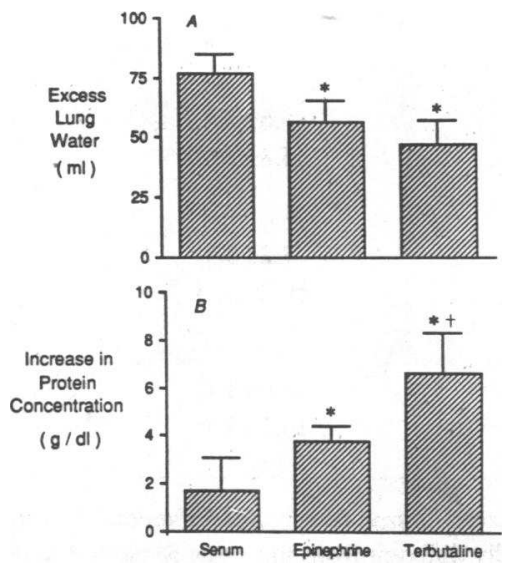

Figure 1. Excess lung water $(A)$ and increase in protein concentration of the airway liquid $(B)$ when serum alone ( $n$ $=6$ ), serum mixed with epinephrine $(n=6)$, and serum mixed with terbutaline $(n=6)$ were instilled into a sheep lung. (*) Statistically different from the value for serum alone. $(\dagger)$ Statistically different from the value for epinephrine. 
Table I. Pulmonary Hemodynamics and Mean Airway Pressures after Instillation of Serum alone or Serum Mixed with Beta-adrenergic Agonists into Sheep Lung

\begin{tabular}{lllll}
\hline Condition & Pulmonary artery pressure & Left atrial pressure & Cardiac output & Mean airway* pressure \\
& $c m H_{2} \mathrm{O}$ & $c m H_{2} \mathrm{O}$ & $l / m i n$ & \\
Serum alone $(n=6)$ & & & & \\
Baseline & $18.3 \pm 5.2$ & $4.4 \pm 1.8$ & $4.2 \pm 1.6$ & $11.8 \pm 1.0$ \\
Experimental & $19.2 \pm 5.2$ & $3.3 \pm 2.6$ & $3.7 \pm 1.4$ & $12.3 \pm 1.9$ \\
Epinephrine $(n=6)$ & & & & $11.2 \pm 2.2$ \\
Baseline & $17.1 \pm 2.1$ & $3.5 \pm 1.4$ & $4.3 \pm 0.9$ & $13.1 \pm 2.3^{\ddagger}$ \\
Experimental & $19.9 \pm 3.1$ & $1.8 \pm 1.3$ & $4.0 \pm 0.7$ & \\
Terbutaline $(n=6)$ & & & & $10.8 \pm 1.1$ \\
Baseline & $19.0 \pm 4.5$ & $4.1 \pm 1.6$ & $3.6 \pm 0.5$ & $12.8 \pm 1.1^{\ddagger}$ \\
Experimental & $19.0 \pm 3.5$ & $2.9 \pm 1.6^{\ddagger}$ & $3.3 \pm 0.4$ & \\
\hline
\end{tabular}

Values are mean $\pm 1 \mathrm{SD}$. * Mean airway pressure $=$ peak airway pressure $/ 2+$ positive end-expiratory pressure $/ 2$. ${ }^{\ddagger}$ Statistically different from baseline value $(P<0.05)$.

significance. Parallel to the liquid clearance, the protein concentration of the airway liquid aspirated after the 4-h experiment was greater than the protein concentration of the instilled serum for all three treatments but was greater for terbutaline and epinephrine than for serum alone (Fig. $1 B$ ). The increase in protein concentration for the terbutaline experiments was also greater than that for the epinephrine experiments.

After serum was instilled either alone or with a beta-adrenergic agonist, the only significant hemodynamic change was a slight decrease in left atrial pressure in the terbutaline group. Also, there was a slight increase in the mean airway pressure in the beta-adrenergic-treated groups although the mean airway pressure was not different between the three groups (Table I). However, lung lymph flow and excess lymph flow increased and the lymph to plasma protein concentration ratio decreased significantly in all three groups of experiments (Table II). Both of these changes were greater after terbutaline and epinephrine than after serum alone (Table II). Arterial oxygen tension decreased, although it was always $>85 \mathrm{mmHg}$.

Instilled and intravenous adrenergic agonist effects. In three preliminary experiments where terbutaline was given intravenously instead of being mixed with the serum, the excess lung water was $60.6 \pm 4.9 \mathrm{ml}$, significantly less than the value for the serum alone experiments $(76.8 \pm 8.0 \mathrm{ml}$ from series 1$)$. The dose of intravenous terbutaline we used had no hemodynamic effect other than a $38 \%$ increase in cardiac output. We therefore studied the effect of both intravenous and instilled terbutaline in three sheep. Terbutaline given by these two routes did not produce an additive effect on lung liquid clearance. Excess lung water for intravenous plus instilled terbutaline $(49.5 \pm 12.7 \mathrm{ml})$ was not significantly different from excess lung water for instilled terbutaline alone from series $1(46.9 \pm 10.5 \mathrm{ml})$.

The changes in pulmonary arterial, left atrial, and peak airway pressures were not different from the pressure changes observed for instilled terbutaline alone. However, the presence of an intravenous infusion of terbutaline did increase cardiac output by $28 \%$ over baseline. The excess lymph flow over $4 \mathrm{~h}$ was $16.2 \pm 3.2 \mathrm{ml}$ and the lymph-to-plasma protein concentration ratio decreased from $0.73 \pm 0.04$ to $0.55 \pm 0.09$. These changes were similar to those observed for instilled terbutaline and were significantly different from changes in excess lymph flow and lymph-to-plasma protein concentration ratio observed in the serum alone experiments in series 1 .

Beta-adrenergic antagonist effects. Propranolol alone did not

Table II. Lymph Flow and Protein Dynamics after Instillation of Serum Alone or Serum Mixed with Beta-adrenergic Agonists

\begin{tabular}{llll}
\hline Condition & Lymph flow & Excess lymph flow* during $4 \mathrm{~h}$ & Protein concentration ratio \\
\hline & $g / h$ & $m l$ & lymph/plasma \\
Serum alone $(n=5)$ & & & $0.76 \pm 0.03$ \\
Baseline & $5.6 \pm 2.4$ & $4.7 \pm 2.8$ & $0.70 \pm 0.07^{\ddagger}$ \\
Experimental & $6.8 \pm 2.6^{\ddagger}$ & & $0.69 \pm 0.09$ \\
Epinephrine $(n=6)$ & & & $0.54 \pm 0.08^{\ddagger \S}$ \\
Baseline & $7.2 \pm 3.5$ & $12.1 \pm 6.5^{\S}$ & \\
Experimental & $10.2 \pm 3.6^{\ddagger}$ & & $0.71 \pm 0.05$ \\
Terbutaline $(n=5)$ & & & $0.54 \pm 0.04^{\ddagger 8}$ \\
Baseline & $5.4 \pm 2.1$ & $19.4 \pm 8.4^{\S}$ &
\end{tabular}

Values are mean $\pm 1 \mathrm{SD} . \quad *$ Excess lymph flow $=[($ experimental lymph flow-baseline lymph flow $) \times 4] .{ }^{\ddagger}$ Statistically different from baseline value $(P<0.05)$. ${ }^{\S}$ Statistically different from the value for serum alone $(P<0.05)$. 
decrease lung liquid clearance. The excess lung water and the increased protein concentration in the airway liquid when propranolol was given intravenously and mixed in the serum were not different from the results with serum alone (Fig. 2). The results were similar regardless of the concentration of propranolol in the instilled serum $\left(10^{-4} \mathrm{M}\right.$ or $\left.10^{-3} \mathrm{M}\right)$. The only significant hemodynamic differences were a $20 \%$ decrease in cardiac output below baseline and a higher mean left atrial pressure during the experiment $\left(7.6 \pm 2.1 \mathrm{~cm} \mathrm{H}_{2} \mathrm{O}\right)$ than for the baseline. This mean left atrial pressure was statistically different from the left atrial pressure measured in the serum-alone experiment $(3.3 \pm 2.6 \mathrm{~cm}$ $\left.\mathrm{H}_{2} \mathrm{O}\right)$, but the cardiac output $(3.4 \pm 1.4 \mathrm{l} / \mathrm{min})$ was not statistically different from the cardiac output measured in the serum alone experiments $(3.7 \pm 1.4 \mathrm{l} / \mathrm{min})$.

In the four experiments where both propranolol and terbutaline were given, the effect of terbutaline on lung liquid clearance and protein concentration in the air spaces was completely blocked (Fig. 2). Except for a higher left atrial pressure (6.5 $\left.\pm 2.1 \mathrm{~cm} \mathrm{H}_{2} \mathrm{O}\right)$, the changes in hemodynamics and lung lymph flow were not different from the values for control experiments with serum alone.

Pulmonary blood flow. Pulmonary blood flow to the seruminstilled lobe decreased in the serum-alone experiments to $20 \%$ of baseline values and did not change over $4 \mathrm{~h}$ (Fig. 3). However, after the beta-adrenergic agonists, the blood flow decreased much less (to $\sim 75 \%$ of baseline). Furthermore, the blood flow recovered to baseline levels by $2 \mathrm{~h}$. At $4 \mathrm{~h}$ it was even slightly above baseline levels. After intravenous nitroprusside, the pulmonary blood flow distribution to the serum-instilled lobe was similar to the results with beta-adrenergic agonists (Fig. 3).
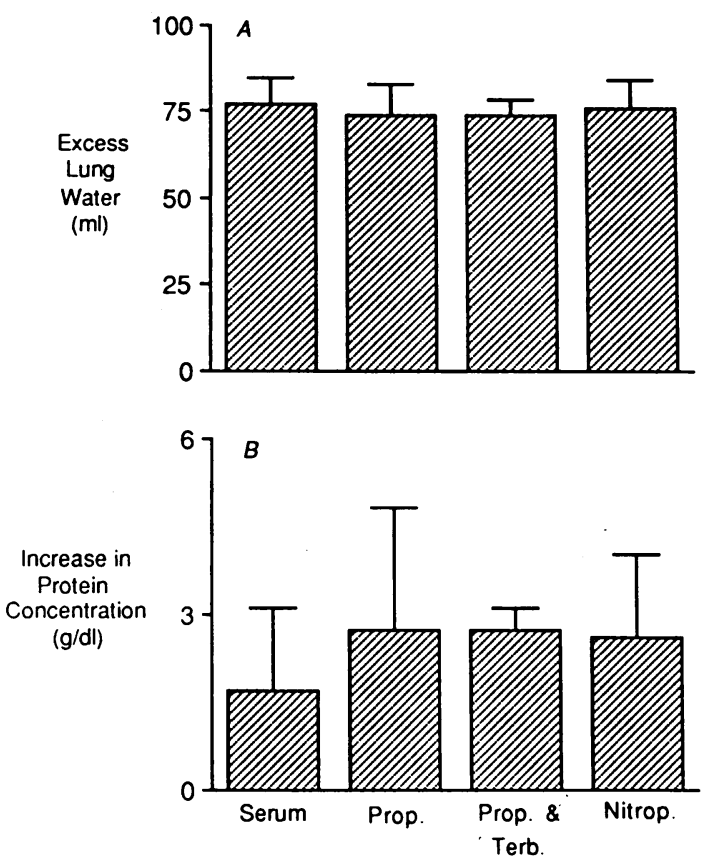

Figure 2. Excess lung water $(A)$ and increase in protein concentration of airway liquid $(B)$ after various treatments: instilled serum alone ( $n$ $=6$ ), instilled serum mixed with propranolol $(n=4)$, instilled serum mixed with propranolol and terbutaline plus intravenous infusion of propranolol and terbutaline $(n=4)$, instilled serum plus intravenous nitroprusside $(n=4)$. There was no statistical difference between any groups.

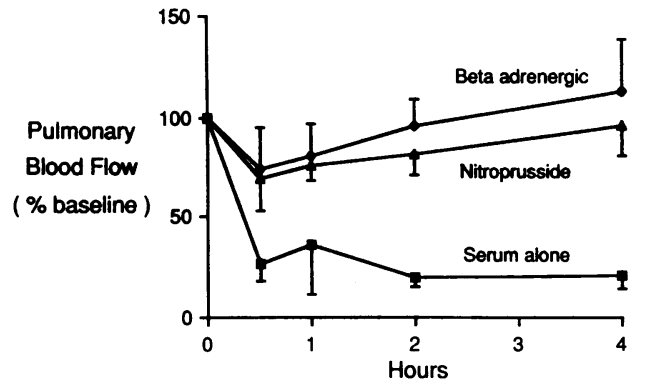

Figure 3. Changes of pulmonary blood flow at $0.5,1,2$, and $4 \mathrm{~h}$ after instillation of serum alone $(n=2)$, serum mixed with a beta-adrenergic agonist (terbutaline, $n=2$; epinephrine, $n=3$ ), and nitroprusside $(n=3)$. The terbutaline and epinephrine groups have been pooled because their effect was similar. The pulmonary blood flow of the serumalone experiments was statistically lower than the pulmonary blood flow of the experiments with beta-adrenergic agonists or nitroprusside at $0.5,1,2$, and $4 \mathrm{~h}$ after serum instillation.

However, even though nitroprusside produced changes in pulmonary blood flow similar to those observed with beta-adrenergic agonists, it did not increase lung liquid clearance. In the four experiments with nitroprusside, excess lung water and the increased protein concentration of the airway liquid were not different from values for serum alone (Fig. 2).

After nitroprusside, pulmonary arterial pressure decreased significantly, from $17.7 \pm 4.4 \mathrm{mmHg}$ in the baseline period to $15.7 \pm 5.0 \mathrm{mmHg}$ in the experimental period. Cardiac output and left atrial pressure did not change. The excess lymph flow over $4 \mathrm{~h}$ was $16.5 \pm 11.2 \mathrm{ml}$ but the lymph-to-plasma protein concentration ratio $(0.72 \pm 0.09)$ was not significantly different from baseline $(0.77 \pm 0.04)$. The excess in lymph flow, but not the lymph-to-plasma protein ratio, was statistically different from those measured for serum alone in series 1.

Sodium channel blocker (amiloride). Amiloride completely blocked the effect of terbutaline on lung liquid clearance (Fig. 4). When either $10^{-4} \mathrm{M}$ or $10^{-3} \mathrm{M}$ amiloride was added to serum mixed with terbutaline, the excess lung water was not different from that for serum alone. In addition, the increased protein concentration of the airwayliquid for terbutaline and amiloride $(1.2 \pm 0.5 \mathrm{~g} / \mathrm{dl})$ was not significantly different from that for serum alone $(1.7 \pm 1.5 \mathrm{~g} / \mathrm{dl})$.

Hemodynamics were similar to those measured for serum alone. The excess lymph flow over $4 \mathrm{~h}$ with amiloride (10.6 \pm 5.9 $\mathrm{ml})$ was greater than that with serum alone $(4.7 \pm 2.8 \mathrm{ml})$, but this difference did not quite reach statistical significance $(P<0.1)$. The lymph-to-plasma protein concentration ratio $(0.68 \pm 0.09)$ was not significantly different from baseline $(0.72 \pm 0.09)$ and the ratio was not different from the one observed with serum alone.

Permeability and surface area evaluation. Both the clearance

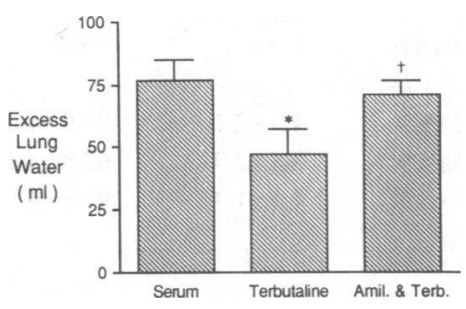

Figure 4. Excess lung water when serum alone $(n=6)$, serum mixed with terbutaline $(n=6)$, or serum mixed with terbutaline and amiloride $(n=4)$ was instilled. (*) Statistically different from the value for serum alone. $(\dagger)$ Statistically different from the value for terbutaline. 
of protein ( ${ }^{125} \mathrm{I}$-albumin) and the accumulation of plasma equivalents in the air spaces $\left({ }^{131} \mathrm{I}\right.$-albumin) provide evidence that the permeability of the alveolar barrier to protein was not increased by beta-adrenergic agonists. Clearance of ${ }^{125} \mathrm{I}$-albumin from the lung into the plasma and lymph was not increased when terbutaline or epinephrine was mixed with the serum (Table III). Furthermore, the concentration of ${ }^{125} \mathrm{I}$-albumin tracer in the final airway liquid sample paralleled the concentration of the native protein shown in Fig. $1 \mathrm{~B}$. Recovery of ${ }^{125} \mathrm{I}$-albumin in the plasma, lymph, and lung in the propranolol, nitroprusside, and amiloride experiments was also not different from that for control experiments with serum alone.

Based on the ${ }^{131} \mathrm{I}$-albumin studies, the estimated accumulation of plasma equivalents in the air spaces was not different when terbutaline or epinephrine was instilled with serum than when serum alone was instilled $(3.3 \pm 2.6,7.3 \pm 3.6$, and $3.8 \pm 2.6$ $\mathrm{ml}$, respectively). Similarly, plasma equivalents in the presence of the other agents (propranolol alone, nitroprusside, and amiloride added to terbutaline, $2.1 \pm 2.1,1.4 \pm 0.1,2.3 \pm 0.1 \mathrm{ml}$, respectively) were not different from each other or the value for serum alone.

The clearance of the smaller tracer molecule $\left[{ }^{57} \mathrm{Co}\right]$ cyanocobalamine provides evidence that neither the surface area for reabsorption nor the permeability of the alveolar barrier was increased by beta-adrenergic agonists. When either terbutaline or epinephrine was instilled along with serum, the percent of $\left[{ }^{57} \mathrm{Co}\right]$ cyanocobalamine recovered from the lung at $4 \mathrm{~h}$ $(90.1 \pm 14.1 \%)$ was not different from the percent recovered when serum alone was instilled $(90.2 \pm 8.6 \%)$. Since the clearance of the $\left[{ }^{57} \mathrm{Co}\right]$ cyanocobalamine tracer, like the clearance of protein, did not increase, the concentration of tracer in the air spaces increased parallel to the concentration of the native protein. Thus, after $4 \mathrm{~h}$, the concentration of tracer in the airway liquid had increased by $21.8 \pm 4.8 \%$ in the presence of serum alone and by $82.2 \% \pm 31.3 \%$ in the presence of terbutaline or epinephrine.

\section{Discussion}

This study demonstrates that beta-adrenergic agonists increase lung liquid clearance in anesthetized intact adult sheep. We found that when either terbutaline or epinephrine was instilled along with serum into the air spaces, the volume of cleared liquid was twice as great as when serum alone was instilled. The importance of this beta-adrenergic effect is more apparent when compared with our previous work in unanesthetized sheep in which serum alone was instilled. In those sheep, $40.8 \pm 8.0 \mathrm{ml}$

Table III. Recovery of ${ }^{125}$ I-albumin Tracer Instilled in Serum Alone and Serum Mixed with Beta-adrenergic Agonists

\begin{tabular}{lllll}
\hline & & \multicolumn{2}{l}{ Recovery of ${ }^{125}$ I-albumin (\% of total instilled) } \\
\cline { 3 - 5 } Experiment & $n$ & $\begin{array}{l}\text { Lung } \\
\text { homogenate }\end{array}$ & $\begin{array}{l}\text { Plasma and } \\
\text { lymph }\end{array}$ & Total \\
\hline Serum alone & 6 & $96.2 \pm 3.9$ & $1.7 \pm 2.1$ & $97.9 \pm 4.0$ \\
Terbutaline & 6 & $90.7 \pm 5.9$ & $3.1 \pm 2.7$ & $93.8 \pm 4.1$ \\
Epinephrine & 6 & $96.7 \pm 5.9$ & $1.1 \pm 1.1$ & $97.8 \pm 5.4$ \\
\hline
\end{tabular}

Values are mean \pm 1 SD. of lung liquid was left in the lung after $12 \mathrm{~h}$ (5). However, in sheep given terbutaline, about the same amount of lung liquid was left in the lung $(46.9 \pm 6.5 \mathrm{ml})$ after only $4 \mathrm{~h}$.

There is a trend toward terbutaline having a greater effect than epinephrine because the mean excess lung water is $12 \mathrm{ml}$ less after terbutaline than after epinephrine, and also because the protein concentration of the airway liquid is significantly greater after terbutaline $(13.2 \pm 1.9 \mathrm{~g} / \mathrm{dl})$ than after epinephrine $(9.8 \pm 0.7 \mathrm{~g} / \mathrm{dl})$. However, the difference in liquid clearance was not statistically significant, probably because the beta error (51\%) was too large.

To determine if terbutaline administered by another route would have an effect similar to that produced by instillation, we gave terbutaline intravenously in a dose that we previously had found to be well tolerated hemodynamically in unanesthetized sheep (17). Since intravenous terbutaline increased lung liquid clearance slightly, in series 2 we attempted to maximize clearance by giving terbutaline both intravenously and in the instilled serum. However, there was no additional effect beyond that for instilled terbutaline $\left(10^{-5} \mathrm{M}\right)$ alone (series 1$)$. The reason that there was no additive effect may be that a maximal or nearmaximal effect of the beta agonist was achieved with $10^{-5} \mathrm{M}$ terbutaline in the instilled serum, although we did not do dose response curves to establish this with certainty. However, in isolated type II alveolar epithelial cells, $10^{-5} \mathrm{M}$ is on the plateau of the dose-response curve for the effect of terbutaline on dome formation (13), which suggests that $10^{-5} \mathrm{M}$ terbutaline in instilled serum provides a near-maximal effect. To evaluate the possibility of achieving a more dramatic effect with intravenous terbutaline alone, we would have had to use higher doses of terbutaline. However, higher doses would alter pulmonary hemodynamics, thus making interpretation of the results more difficult.

The experiments with the beta-blocker propranolol indicate that the effect of terbutaline on lung liquid clearance is mediated through beta receptors. Although we did not specifically attempt to block the effects of epinephrine, it is likely that these effects were also mediated by stimulation of beta receptors. Experimental work with isolated alveolar type II cells supports this hypothesis. In these cells, alpha-adrenergic agonists did not increase the numbers of domes formed (13). However, specific experiments with alpha-blockers and agonists would be needed to independently assess this issue in our model. Another finding from these experiments is that basal beta-adrenergic tone in anesthetized sheep is probably not an important factor in the normal clearance of liquid across the alveolar barrier because propranolol alone did not have an effect on lung liquid clearance. Similarly, in isolated alveolar type II cells, the presence of propranolol alone did not decrease the basal number of domes formed (13).

Our study was also designed to determine which mechanisms are important in increasing lung liquid clearance in the presence of beta-adrenergic agonists. The most likely mechanism appears to be a stimulatory effect on active transport of sodium across the alveolar barrier with passive movement of chloride and water. The most direct evidence in this study implicating a sodiumdependent mechanism is provided by the experiments with the sodium channel blocker amiloride. Amiloride, at either $10^{-3} \mathrm{M}$ or $10^{-4} \mathrm{M}$, completely blocked the effects of terbutaline on lung liquid clearance. In prior experiments, when we instilled amiloride alone $\left(10^{-3}\right.$ or $\left.10^{-4} \mathrm{M}\right)$ with serum, lung liquid clearance decreased by $39 \%$ (2). In view of these prior results, we anticipated that when amiloride was added to serum mixed with terbutaline 
(series 5), lung liquid clearance would be slightly less than when serum alone was instilled. However, the lung liquid clearance in these two conditions was similar (Fig. 4). Recently, Goodman et al. (26) reported similar results. In the isolated, perfused rat lung, amiloride alone reduced sodium transport from the airspaces by $30 \%$, terbutaline increased it by $59 \%$, but terbutaline plus amiloride decreased clearance by only $14 \%$. The most reasonable explanation for these findings is that terbutaline stimulates sodium transport through both amiloride-sensitive and insensitive pathways. These pathways have been documented in both freshly isolated type II cells (27), in the intact dog tracheal epithelium (28), and in sheep segmental bronchial epithelium (29). Thus, our results suggest that an increase in active transport of sodium is the likely mechanism for the increased lung liquid clearance induced by beta-adrenergic agonists. These results in intact adult sheep are similar to results obtained in other experimental work with fetal lambs (11), isolated rat lungs (12), and isolated alveolar type II cells $(10,13)$.

We also considered the role of other possible mechanisms for increasing lung liquid clearance in the presence of beta-adrenergic agonists. First, we considered the possible contribution of changes in pulmonary hemodynamics. When either terbutaline or epinephrine was instilled in the lung, there were no important changes in the pulmonary hemodynamics or mean airway pressure. Although these measurements do not precisely assess lung microvascular pressure, they indicate that changes in hemodynamics did not have a major influence on the effects of beta-adrenergic agents.

However, the absence of overall changes in pulmonary hemodynamics does not eliminate the possibility that changes in pulmonary blood flow to the serum-instilled lung might have influenced the rate at which liquid was cleared from the lung. When we evaluated this possibility, we found that both terbutaline and epinephrine substantially inhibited the decrease in pulmonary blood flow that occurs when serum alone is instilled into the air spaces of the lung (Fig. 3). To determine if preservation of pulmonary blood flow to the serum-instilled lung is an important mechanism for the increased lung liquid clearance observed with beta-adrenergic agents, we studied the effects of nitroprusside, the vasodilator, on both liquid clearance and pulmonary blood flow (series 4). We found that nitroprusside inhibited the decrease in pulmonary blood flow to the serum-instilled lobe as effectively as terbutaline or epinephrine (Fig. 3). However, nitroprusside had no effect on lung liquid clearance (Fig. 2). Therefore, it is unlikely that the increased lung liquid clearance induced by terbutaline or epinephrine is mediated by the preservation of pulmonary blood flow to the serum-instilled lung.

These results on the blood flow distribution to the seruminstilled lung also provide interesting information on the role of blood flow in lung liquid clearance in general. Because the lung liquid clearance of serum alone $(76.8 \pm 8.0 \mathrm{ml})$ and of serum plus intravenous nitroprusside $(76.0 \pm 8.2 \mathrm{ml})$ were similar but changes in pulmonary blood flow were very different in each situation (Fig. 3), we think that lung liquid clearance is independent of blood flow as long as a minimal amount of blood flow can be maintained. This hypothesis is also supported by our analysis of the rate of lung liquid clearance from the homogenous blue area (where $70 \%$ of the liquid is instilled) compared with the rate of clearance from the nonhomogenous blue area. In the serum-alone experiments, the blood flow decreased to $25 \%$ of the baseline in the homogenous area, and we calculated that $35 \%$ of the liquid instilled in this region was cleared. In the nonhomogenous blue area, where $30 \%$ of the liquid was instilled, the blood flow decreased to only $49 \%$ of the baseline, and we calculated that $37 \%$ of the liquid instilled in this region was removed. Thus the rate of liquid clearance was not influenced by these differences in regional blood flow. However, from these experiments we cannot determine the lowest level of pulmonary blood flow at which liquid can still be cleared from the air spaces and the lung.

The increase in lung lymph could be a mechanism for the increased lung liquid clearance since adrenergic agonists can increase lymphatic pumping activity (30). In fact, when serum alone was instilled, there was an increase in lymph flow that could account for $20 \%$ of the lung liquid that was cleared. When terbutaline was added to the serum, the increase in lymph flow was greater and could have accounted for $36 \%$ of the liquid clearance (Table IV). However, even if the fraction of liquid cleared through the lymphatic system is greater with terbutaline, the overall increase in lymph flow still accounted for less than half of the total excess of liquid removed from the lung (Table IV). Thus, the increase in lymph flow alone cannot explain the increased lung liquid clearance induced by the beta-adrenergic agonists. Furthermore, we have previously hypothesized that when a protein solution is instilled in the air spaces some of the increase in lymph flow originates from increased microvascular filtration (3). This hypothesis is supported by the results of the nitroprusside experiments where excess lung lymph flow was $11.8 \mathrm{ml}$ higher than with serum alone but the lung liquid clearance was not different between the two types of experiments (Table IV). Also it has been reported in other studies that increased pulmonary blood flow without any changes in microvascular pressure can increase lung lymph flow (31).

Thus, some of the 19.4-ml increase in lung lymph in the serum-plus-terbutaline studies probably is related to the increase in pulmonary blood flow to the serum-instilled lobe that occurs with beta-adrenergic therapy (Fig. 3). In fact, since excess lymph flow was $10.6 \mathrm{ml}$ in the serum-plus-terbutaline and amiloride experiments, compared with $4.7 \mathrm{ml}$ in the serum-alone experiments (while lung liquid clearance was the same), it is likely that the 5.9-ml difference in lymph flow represents the beta-adrenergic effect of terbutaline on blood flow and filtration, which amiloride should not block. The greater excess lymph flow $(19.4 \mathrm{ml})$ in the serum-plus-terbutaline experiments, compared with the 10.6 $\mathrm{ml}$ in the serum-plus-terbutaline and amiloride studies, probably reflects the addition of liquid from the airspaces. The $8.8-\mathrm{ml}$ difference in lymph flow accounts for $\sim 30 \%$ of the excess liquid cleared from the lung in the presence of beta-adrenergic therapy with terbutaline.

Table IV. Relationship of Lung Lymph Flow to Lung Liquid Clearance Over Four Hours in Anesthetized Sheep

\begin{tabular}{lccl}
\hline Condition & $n$ & $\begin{array}{l}\text { Excess lung } \\
\text { lymph (ML) }\end{array}$ & $\begin{array}{l}\text { Total liquid } \\
\text { removed (ML) }\end{array}$ \\
\hline Serum alone & 6 & $4.7 \pm 2.8^{\ddagger}$ & $23.6 \pm 10.5$ \\
Serum + terbutaline & 6 & $19.4 \pm 8.4$ & $53.4 \pm 11.2$ \\
Serum + nitroprusside & 4 & $16.5 \pm 11.2$ & $27.1 \pm 9.0$ \\
\hline
\end{tabular}

* Excess lung lymph $=$ lymph flow $(\mathrm{ml} / \mathrm{h})$ after serum instilled minus baseline lymph flow $\times 4 \mathrm{~h}$.

${ }^{\ddagger}$ Mean \pm SD.

${ }^{\S}$ Calculated as volume of liquid instilled minus residual excess water in experimental lung. 
The last two mechanisms for the increased lung liquid clearance induced by beta-adrenergic agonists that we considered were increased alveolar barrier permeability and increased alveolar surface area available for reabsorption. However, neither of these variables increased. In contrast to lung liquid clearance, the clearance of protein from the air spaces was not increased by beta-adrenergic agonists as measured either by the lymph or plasma concentrations or by the residual tracer left in the lung. The low rate of protein clearance is, in fact, similar to that previously reported in both anesthetized sheep (3) and unanesthetized sheep (5). Our finding that protein clearance was not increased demonstrates that the permeability of the alveolar barrier to large molecules is not increased by beta-adrenergic agonists. Unchanged alveolar barrier permeability is also supported by our finding that the movement of the plasma protein tracer $\left({ }^{131} \mathrm{I}\right.$ albumin) into the air spaces and the clearance of the $\left[{ }^{57} \mathrm{Co}\right]$ cyanocobalamine from the air spaces were minimal and similar for the beta-adrenergic agonists mixed with serum and for serum alone.

The surface area available for reabsorption could have increased if the bronchodilators and vasodilators terbutaline or epinephrine opened or dilated some small airways or capillaries. If there had been a significant increase in alveolar surface area with either of these agents, we would have expected greater clearance of $\left[{ }^{57} \mathrm{Co}\right]$ cyanocobalamine $(1,355 \mathrm{~mol} \mathrm{wt})$ than of ${ }^{125} \mathrm{I}$ albumin $(69,000 \mathrm{~mol} \mathrm{wt})$. But the clearance of both tracers was similar. Furthermore, the concentrations of ${ }^{125} \mathrm{I}$-albumin and $\left[{ }^{57} \mathrm{Co}\right]$ cyanocobalamine in the airway liquid rose in parallel to the concentration of native protein, which is what we would expect if their clearances were similar but the clearance of small solutes, such as sodium, was increased by beta-adrenergic agonists. Thus, it appears that movement of small solutes and water across the alveolar barrier can be increased without either an increase in alveolar barrier permeability to molecules with a $>1,000 \mathrm{~mol}$ wt or an increased surface area for reabsorption. Similarly, Crandall et al. (12) have reported that terbutaline increased sodium transport without increasing sucrose transport across the alveolar barrier of an isolated rat lung.

These slow rates of clearance for the ${ }^{125} \mathrm{I}$-albumin and $\left[{ }^{57} \mathrm{Co}\right]$ cyanocobalamine tracers and the accumulation of ${ }^{131} \mathrm{I}$ albumin in the airspaces also support our original observations $(3,5)$ that the instillation of autologous serum into the airspaces does not cause an injury to the alveolar barrier. However, it is possible that instillation of serum into the airspaces releases mediators that could influence lung liquid clearance.

Thus, changes in pulmonary hemodynamics, regional pulmonary blood flow, lung lymph flow, and alveolar barrier permeability and surface area available for absorption of liquid do not account for the effects of beta-adrenergic agonists on increased lung liquid clearance.

The results for liquid and protein clearance are also internally consistent. Since protein clearance from the air spaces and the lungs as a whole was not increased by beta-adrenergic agonists, we would have expected an increase in the alveolar protein concentration roughly proportional to the volume of liquid that was cleared from the lung. This is what we found when we combined the data for all the experiments. The relationship between these two variables was significant, with an $R$ value of 0.77 .

Another approach to establishing the internal consistency of the results is to use a proportion calculation to estimate the volume of liquid that would be expected to remain in the air spaces. Since we know the volume of serum instilled, its protein concentration, and the final protein concentration in the airway liquid, we can solve for $\mathrm{A}$, the expected volume remaining in the air spaces. For example, in the serum-alone experiments, we instilled $108 \mathrm{ml}$ with a protein concentration of $6.6 \mathrm{~g} / \mathrm{dl}$. The airway liquid had a final protein concentration of $8.2 \mathrm{~g} / \mathrm{dl}$. Thus, $108 \mathrm{ml} \times 6.6 \mathrm{~g} / \mathrm{dl}=\mathrm{A} \times 8.2 \mathrm{~g} / \mathrm{dl} ; \mathrm{A}=86.9 \mathrm{ml}$. This calculation is based on the assumption that most of the protein left in the lung is in the airspaces, not in the interstitium. This assumption is well supported by the small quantities of ${ }^{125} \mathrm{I}$-albumin in the lymph over $4 \mathrm{~h}$ as well as our prior lavage studies demonstrating that $>85 \%$ of the instilled protein was in the airspaces after 4 h (32). However, since a small fraction of the instilled protein does leave the air spaces over $4 \mathrm{~h}$, to make this calculation more accurate, we multiplied the protein concentration in the instillate by the residual amount of protein tracer ( ${ }^{125} \mathrm{I}$-albumin) in the lung (Table III). Second, since A should be the water volume and not the serum volume, we multiplied $A$, the expected volume remaining in the air spaces, by the wet/dry ratio of the airway liquid. Using these two adjustments, A equals 81.0 instead of $86.9 \mathrm{ml}$. This value is remarkably close to the measured value of $76.8 \pm 8 \mathrm{ml}$. No adjustment is needed for the final protein concentration since the ${ }^{131} \mathrm{I}$-albumin data indicate that very little plasma protein was added to the alveolar space. When we made the same calculations for all the experiments in series 1 , we found that the estimated volume in the air spaces was $41.8 \mathrm{ml}$ for terbutaline vs. a measured value of $46.9 \mathrm{ml}$, and $54.3 \mathrm{ml}$ for epinephrine versus a measured value of $56.9 \mathrm{ml}$.

The difference between the calculated alveolar volume and the measured lung water should be the excess water or volume in the interstitium. Because we found that the calculated and measured volumes were similar, we think that the excess water we measured is mainly in the air spaces (alveoli). Although our method of measuring lung water does not provide a direct measure of alveolar volume because we are measuring excess water in the whole lung, this last evidence supports the hypothesis that the main barrier to liquid and protein clearance is the bronchoalveolar epithelium and not the interstitium.

Whole animal studies are not designed to determine the precise sites of liquid reabsorption from the airspaces. Reabsorption could occur through the alveolar epithelium or the bronchial epithelium. However, there is some evidence that favors the alveolar level as the primary location for liquid reabsorption. First, the alveolar surface area provides a larger area for reabsorption than the distal airways. Second, recent work (33) demonstrated a $300 \%$ greater density of beta receptors in the alveolar wall than the bronchial epithelium. Finally, Ballard et al. (34) recently reported that reabsorption can occur at the alveolar level in the isolated rat lung by advancing the liquid into the alveoli with an immiscible fluorocarbon.

In conclusion, we have found that lung (i.e., alveolar) liquid clearance is increased by beta-adrenergic agonists in anesthetized, ventilated adult sheep. This increase is mediated through beta receptors, and the mechanism appears to depend on stimulation of active sodium transport from the air spaces into the interstitium across the alveolar barrier. These results provide further evidence in intact adult animals that active transport of solute (sodium) can play a role in alveolar and lung liquid clearance, as has been suggested by work done in preparations such as isolated alveolar type II cells $(7,9)$, isolated perfused lungs (12), and intact fetal lambs (4). 


\section{Acknowledgments}

The authors thank Oscar Osorio and Michael Grady for their technical assistance, Bernie Baccay and Gaea Aguilar for their secretarial assistance, Mimi Zeiger for her editorial assistance, and Dr. Julien I. E. Hoffman for his comments on the statistical analysis.

Dr. Berthiaume was supported by a Centennial fellowship from the Medical Research Council of Canada. This study was supported in part by National Institutes of Health Program Project Grant No. HL-25816.

\section{References}

1. Taylor, A. E., A. C. Guyton, and V. S. Bishop. 1965. Permeability of the alveolar membranes to solutes. Circ. Res. 16:353-362.

2. Staub, N. C. 1983. Alveolar flooding and clearance. Am. Rev Respir. Dis. 127:S44-S55.

3. Matthay, M. A., C. C. Landolt, and N. C. Staub. 1982. Differential liquid and protein clearance from the alveoli of anesthetized sheep. $J$. Appl. Physiol. 53:96-104.

4. Olver, R. E. 1983. Fluid balance across the fetal alveolar epithelium. Am. Rev. Respir. Dis. 127:S33-S36.

5. Matthay, M. A., Y. Berthiaume, and N. C. Staub. 1985. Long term clearance of liquid and protein from the lungs of unanesthetized sheep. J. Appl. Physiol. 59:928-934.

6. Olver, R. E., and L. B. Strang. 1974. Ion fluxes across the pulmonary epithelium and the secretion of lung liquid in the fetal lamb. J. Physiol 241:327-357.

7. Mason, R. J., M. C. William, J. H. Widdicombe, M. J. Sanders, D. S. Misfeldt, and L. C. Berry. 1982. Transepithelial transport by pulmonary alveolar type II cells in primary culture. Proc. Natl. Acad. Sci. U.S.A. 79:6033-6037.

8. Goodman, B. E., and E. D. Crandall. 1982. Dome formation in primary cultured monolayers of alveolar epithelial cells. Am. J. Physiol. 243:C96-C100.

9. Goodman, B. E., R. S. Fleisher, and E. D. Crandall. 1983. Evidence for active $\mathrm{Na}^{+}$transport by cultured monolayers of pulmonary alveolar epithelial cells. Am. J. Physiol. 245:C78-C83.

10. Sugahara, K., J. H. Caldwell, and R. J. Mason. 1984. Electrical currents flow out of domes formed by cultured epithelial cells. J. Cell Biol. 99:1541-1546.

11. Walters, D. V., and R. E. Olver. 1978. The role of catecholamine in lung liquid absorption at birth. Pediatr. Res. 12:239-242.

12. Crandall, E. D., T. A. Heming, R. L. Palombo, and B. E. Goodman. 1986. Effects of terbutaline on sodium transport in isolated perfused rat lung. J. Appl. Physiol. 60:289-294.

13. Goodman, B. E., J. E. Brown, and E. D. Crandall. 1984. Regulation of transport across pulmonary alveolar epithelial cell monolayers. J. Appl. Physiol. 57:703-710.

14. Roos, P. J., J. P. Wiener-Kronish, K. H. Albertine, and N. C. Staub. 1983. Removal of abdominal sources of caudal mediastinal node lymph in anesthetized sheep. J. Appl. Physiol. 55:996-1001.

15. Staub, N. C., R. D. Bland, K. L. Brigham, R. Demling, A. J. Erdmann, and N. C. Woolverton. 1975. Preparation of chronic lung lymph fistulas in sheep. J. Surg. Res. 19:315-320.
16. Freedman, F. B., and J. A. Johnson. 1969. Equilibrium and kinetic properties of the Evans blue albumin system. Am. J. Physiol. 216:675681 .

17. Culver, P. L., W. H. Rao, P. Dodek, and N. C. Staub. 1983. Beta receptors and lung fluid balance in awake sheep. Physiologist. 26:A56. (Abstr.)

18. Zwillich, C. W., M. A. Matthay, D. E. Potts, R. Adler, F. Hofelot, and J. V. Weil. 1978. Thyrotoxicosis: comparison of effects of thyroid ablation and beta-adrenergic blockade on metabolic rate and ventilatory control. J. Clin. Endocrinol. \& Metab. 46:491-500.

19. Selinger, S. L., R. D. Bland, R. H. Demling, and N. C. Staub. 1975. Distribution volumes of ${ }^{131} \mathrm{I}$-albumin, ${ }^{14} \mathrm{C}$ sucrose and ${ }^{36} \mathrm{Cl}$ in sheep lung. J. Appl. Physiol. 39:773-779.

20. Heymann, M. A., B. D. Payne, J. I. E. Hoffman, and A. M. Rudolph. 1977. Blood flow measurements with radio nuclide-labeled particles. Prog. Cardiovasc. Dis. 20:55-79.

21. Staub, N. C., E. L. Schultz, K. Koike, and K. H. Albertine. 1985. Effect of neutrophil migration induced by leucotriene $\mathrm{B}_{\mathbf{4}}$ on protein permeability in sheep lung. Fed. Proc. 44:30-35.

22. Egan, E. A., R. M. Nelson, and I. H. Gessner. 1977. Solute permeability of the alveolar epithelium in acute hemodynamic pulmonary edema in dogs. Am. J. Physiol. 233:H80-H86.

23. Nelson, R. M., B. R. McIntyre, and E. A. Egan. 1978. Solute permeability of the alveolar epithelium in alloxan edema in dogs. $J$. Appl. Physiol. 44:353-357.

24. Kwong, M. S., and E. A. Egan. 1985. Validation of $\left[{ }^{57} \mathrm{Co}\right]$ cyanocobalamine as an extracellular fluid marker and measurements of albumin exclusion from the interstitium in the rabbit. Micro. Res. 29:152-160.

25. Zar, J. H. 1974. Biostatistical Analysis. Prentice-Hall, Inc., Englewood Cliffs, N. J. 620 pp.

26. Goodman, B. E., and E. D. Crandall. 1986. Effects of amiloride on sodium flux in isolated rat lungs. Fed. Proc. 45:1004. (Abstr.)

27. Bland, R. D., and C. A. R. Boyd. 1986. Cation transport in lung epithelial cells derived from fetal, newborn and adult rabbits. Influence of premature birth, labor and postnatal development. J. Appl. Physiol. 61:507-515.

28. Widdicombe, J. H., and M. I. Welsh. 1980. Ion transport by dog tracheal epithelium. Fed. Proc. 39:3062-3066.

29. Cotton, C. U., E. E. Lawson, R. C. Boucher, and J. T. Gatzy. 1983. Bioelectric properties and ion transport of airways excised from adult and fetal sheep. J. Appl. Physiol. 55:1542-1549.

30. Reddy, N., and N. C. Staub. 1981. Intrinsic propulsive activity of thoracic duct perfused in anesthetized dogs. Microvasc. Res. 21:183192.

31. Coates, G., H. M. O'Brodovich, A. C. Jeffries, and G. N. Gray. 1984. Effects of exercise on lung lymph flow in sheep and goats during normoxia and hypoxia. J. Clin. Invest. 74:133-141.

32. Matthay, M. A., R. L. Conhaim, E. L. Schultz, C. C. Landolt, and N. C. Staub. 1981. How serum in the air spaces of sheep lung increases lung lymph flow. Am. Rev. Resp. Dis. 123:247. (Abstr.)

33. Carstairs, J. R., A. J. Nimmo, and P. J. Barnes. 1985. Autoradiographic visualization of beta-adrenoreceptor subtypes in human lung. Am. Rev. Resp. Dis. 132:541-547.

34. Ballard, S. T., R. C. Boucher, and J. T. Gatzy. 1986. Liquid clearance from alveoli of perfused rat lung. Fed. Proc. 45:1013. (Abstr.) 